\title{
La farmacogenómica en el desarrollo de la inmunoterapia específica de alérgenos y autoantígenos.
}

The pharmacogenomic in the development of the autoantigen- and allergen- specific immunotherapy.

Mainet-González D.

DOI. 10.21931/RB/2018.03.03.9

Resumen: Las enfermedades alérgicas y autoinmune son frecuentes en la población, afectan su calidad de vida y pueden provocar la muerte. Las enfermedades alérgicas son una respuesta exagerada a antígenos extraños inocuos y las autoinmune, a los antígenos propios. La inmunoterapia de antígeno específico ha logrado disminuir los síntomas, el consumo de medicamentos y la evolución a formas más graves de las enfermedades alérgicas. Esta enfermedad tratada con esa inmunoterapia ha sido estudiada con algunas técnicas farmacogenómicas en muestras de sangre, células mononucleares de sangre periférica y algunos tejidos con los objetivos de: predecir una respuesta clínica eficaz, en seleccionar a los pacientes que sean posibles respondedores, en determinar las dosis óptimas para esta terapéutica, en buscar combinaciones con otros medicamentos y en estudiar los mecanismos de acción de las diferentes vías de administración de antígenos. Sin embargo, esta inmunoterapia en las enfermedades autoinmune no ha alcanzado buenos resultados a nivel de ensayo clínico como en los estudios preclínicos. A partir de las diferentes aplicaciones de la farmacogenómica en la inmunoterapia de antígeno específico principalmente de las enfermedades alérgicas se hacen algunas consideraciones, que favorezcan una transición óptima de los candidatos más efectivos a ser vacuna en la práctica clínica de las enfermedades autoinmune.

Palabras Claves: genómica, expresión de genes, vacuna o inmunoterapia antígeno específica, diagnosticadores, alergia y autoinmunidad.

\begin{abstract}
Allergic and autoimmune diseases are very frequent in the population, affect his life quality and can provoke death. Allergies are an extraordinary response to undamaged strange antigen and autoimmune diseases, itself antigen. The antigenspecific immunotherapy has gotten to decrease symptoms, the drug consumes and produces a way less dangerous of allergic disease. This illness treated with this immunotherapy has been studied with some pharmacogenomic techniques in blood samples, peripheral blood mononuclear cells, and several tissues for the following objectives: to predict a efficient clinical response, to select highly probable patients that response to the treatment, to determine the optimum dosage or therapeutic schedule, to looking for a new combinations with other treatments, and to study the action mechanism of the different ways to administrate antigens. However, this immunotherapy has not got as good results in the autoimmune-disease clinical trials as preclinical studies. In this paper, some recommendations and suggestions are written after to explain the different applications of the pharmacogenomic researches of the antigen-specific immunotherapy in the allergic disease that permit a good transition of the most effective vaccine candidate to clinical practice of autoimmune diseases.
\end{abstract}

KeyWords: genomic, gene expression, antigen-specific immunotherapy or vaccine, biomarker, allergy and autoimmunity.

\section{Introducción}

Las enfermedades alérgicas afectan desde un 10 al $40 \%$ de la población de los países industrializados según la región geográfica ${ }^{1}$ y a Cuba $^{2}$ y las enfermedades autoinmunes, de 7,6 a 9,4\% de la población ${ }^{3}$.En ambas enfermedades ocurre una respuesta inmune inflamatoria exagerada a antígenos que son inocuos. En las primeras, esos antígenos son extraños al organismo (alérgenos) y en las segundas, contra antígenos propios del organismo (autoantígenos). Las enfermedades alérgicas son menos heterogéneas que las enfermedades autoinmunes. En las primeras, el antígeno diana causante principal de la enfermedad generalmente es conocido, y en las segundas, no se logra identificar esa diana. La inmunopatogénesis de las enfermedades autoinmune está asociada con una expansión epítópica y un daño tisular más importante que las enfermedades alérgicas antes que el diagnóstico se haya completado. En ambas enfermedades está indicado el tratamiento para aliviar los síntomas y el empleo de antiinflamatorios inespecíficos. Sin embargo, la inmunoterapia de antígeno específico (ITAE) juega un papel primordial ya que es capaz de alterar el curso natural de ambas enfermedades.

La ITAE ha sido efectiva en la alergia a picadura de abejas, al ácaro de polvo doméstico, la caspa de mascotas y al polen por vía de administración sublingual o subcutánea. La primera vía es mucho más segura, lo cual favorece la administración por el mismo paciente en su domicilio4,5. Ese tratamiento ha logrado en las enfermedades alérgicas mantener su efecto después de retirado con una remisión larga de los síntomas, previene de nuevas sensibilizaciones a otros alérgenos y disminuye la posibilidad de progresión a formas clínicas más graves de esa enfermedad. Por ejemplo, los pacientes con rinitis alérgicas no lleguen a padecer de asma o anafilaxia. Este tratamiento indicado en los inicios de la enfermedad es mejor para evitar la expansión epitópica o polisensibilización a varios alérgenos. También puede 
llegar a tener un perfil de seguridad y costo-beneficio mejor que los fármacos inmunosupresores inespecíficos o aliviadores de síntomas. En este tratamiento es importante identificar el alérgeno causal clínicamente más relevante para pacientes mono- como polisensibilizados por la historia clínica y los exámenes complementarios.

Los objetivos fundamentales de desarrollo de la ITAE es aumentar la seguridad mediante nuevos esquemas de tratamiento que disminuyen el tiempo de escalamiento gradual de la dosis, consiga una mayor adherencia del paciente al tratamiento y mejoren la efectividad en la inducción de inmunotolerancia. La tolerancia clínica es un estado de no respuesta inmune específica contra antígenos inocuos extraños o propios sin desencadenar síntomas durante largo período de tiempo mediante el aumento del umbral de activación de las células efectoras y cambios en la función de las células T y B de memoria específicas de antígeno ${ }^{6}$. La ITAE ha tenido buenos resultados en los estudios preclínicos con animales modelos de enfermedades autoinmunes, pero no ha logrado esos éxitos en los ensayos clínicos. A excepción de la enfermedad celíaca, que tiene un candidato en ensayo clínico entre la fase I y II; cuyo antígeno desencadenante principal es el gluten ${ }^{7}$.

La farmacogenómica es una parte de la farmacogenética que estudia la influencia de muchos genes con un enfoque sistémico o global en la respuesta al tratamiento farmacológico o inmunológico mediante tecnologías generadoras de gran cantidad de datos: la reacción en cadena de la polimerasa cuantitativa (RCPC), el microrreglo de ácido desoxirribonucleico (ADN), la secuenciación de ácido ribonucleico (ARN) y de ADN. Se ha empleado en el estudio de la ITAE en los modelos preclínicos y en los ensayos clínicos para predecir una respuesta eficaz, en la selección de los pacientes que sean posibles respondedores, en realizar una combinación sinérgicas o aditivas de varios esquemas de tratamiento, en determinar las dosis óptimas de antígeno para esta terapéutica y en el estudio de los mecanismos de acción de las diferentes vías de administración de antígeno. En esta revisión se expone las diferentes metodologías empleadas en las anteriores aplicaciones de los estudios farmacogenómicos de la ITAE principalmente en las enfermedades alérgicas y se realizan algunas recomendaciones para que esta terapéutica mejore sus resultados clínicos en las enfermedades autoinmune.

\section{Monitorear la evolución clínica y predecir la respuesta eficaz al tratamiento.}

El diagnóstico subrogado de la ITAE con el objetivo de monitorear la respuesta al tratamiento y mostrar indicios precoces de su eficacia clínica ha sido investigada en las células dendríticas y células T. En uno de los estudios de las células dendríticas se emplearon 2 estrategias complementarias para comparar los proteomas totales de las células dendríticas efectoras con las células dendríticas tolerogénicas derivada de monocitos in vitro: electroforesis bidimensional y espectrometría libre de marcaje ${ }^{8}$. Los genes diferencialmente expresados fueron confirmados como diagnosticadores posibles en la RCPc en sangre periférica y en Western Blot en una muestra de 79 pacientes. Se identificaron 6 genes relacionados con las células dendríticas efectoras tipo 1 (DC1, favorece la diferenciación de las células T auxiliadoras de tipo 1) y DC17 (favorece la diferenciación de las células T auxiliadoras de tipo 17), y 8 genes relacionados con las células dendríticas regulatorias (DCreg). De los primeros tipos de células no se descubrió ningún gen relacionado con la eficacia clínica. Sin embargo, del segundo grupo de células se descubrieron dos genes: C1Q (gen del componente 1 del complemento) y STAB1 (gen del recep- tor de lipoproteína de baja densidad). La expresión de esos dos genes aumentó en los pacientes respondedores clínicos y no así, en los pacientes no respondedores o tratados como placebo. En el análisis de curva ROC (siglas del inglés, características operacionales del receptor) de esos dos genes se obtuvo un área bajo la curva entre 0,71 a 0,77 ( $p<0.05)$ para el gen C1Q (gen de las subunidades A, B, C del subcomponente Clq del complemento) y 0,71 para el gen STAB1 ( $p=0,0187$ ).

En otro ensayo similar se comparó el perfil transcriptómico y el proteómico de células dendríticas derivadas de monocitos y polarizadas in vitro hacia las DC1, hacia las células dendríticas tipo 2 (DC2, favorece la diferenciación de células T auxiliadoras tipo 2) y hacia DCreg mediante microarreglo amplio del genoma a partir de ADN complementario y proteómica cuantitativa libre de etiquetado, respectivamente ${ }^{9}$. Los genes diferencialmente regulados en DC2 y DCreg fueron evaluados por medio de la RCPc en células mononucleares de sangre periférica de 80 pacientes con alergia al polen de hierba antes y después de 2 a 4 meses de ITAE sublingual, en paralelo con el índice de síntomas de la rinoconjuntivitis. Los genes asociados con DC2: CD141 (gen de la trombomodulina, THBD), GATA3 (gen de la proteína 3 de unión GATA), y RIPK4 (gen de la proteína quinasa serina /treonina 4 de interacción con el receptor) fueron infraexpresado concomitantemente con una sobreexpresión de los genes asociados a las células DCreg: C1QA y FCGR3A [gen del receptor IIIA del fragmento Fc de la inmunoglobulina (lg) G] en sangre de respondedores clínicos y no ocurrió así en los no respondedores. Esos cambios genéticos fueron mejor correlacionados con un beneficio clínico que las alteraciones de las células T CD4+ específica de alérgeno o la respuesta de lgG. La combinación de esos 5 genes expresados en células dendríticas sanguíneas: C1Q, CD141, FCGR3A, GATA3, y RIPK4 (estos tres últimos existentes también en las células linfoides) y conjuntamente con el gen de STAB1 del estudio anterior son posibles diagnosticadores; que reflejan los cambios en el balance regulatorio proalérgico en sangre periférica, permiten monitorear temprano (2 meses) el inicio de la eficacia de ITAE y ser predictivos de la tolerancia clínica. De estos dos estudios independientes sólo el gen C1QA ha sido reproducible.

La búsqueda de diagnosticadores subrogados de eficacia clínica se ha realizado en las células T auxiliares (CD4+) periféricas específicas de polen de hierba (alérgenos $P h l p 1$ y $P h l p 5$ ) provenientes de células mononucleares de sangre periféricas antes, a los 2 meses y a los 4 meses de tratamiento.10 Aunque se logró un mejoramiento de los síntomas en un 29,2 \% de los pacientes que recibieron tabletas de ITAE, la disminución de la expresión de los genes de las citoquinas interleucina-4 o IL-4 (IL4) e IL-10 (IL10) mediante la RCPc y de la secreción de la citoquina IL-10 en los pacientes $(p<0.001)$ fue sin correlación con un beneficio clínico. Se concluyó que los cambios detectados en esas células T auxiliadoras no son diagnosticadores de eficacia temprana del mejoramiento clínico de los pacientes. Sin embargo, en otro estudio los niveles de expresión de los genes de IL17 y RORC (gen del receptor C huérfano del receptor de ácido retinoico) fueron determinados por la RCPc de ARN total extraído de las células mononucleares periféricas in vivo y ex vivo ${ }^{11}$. Los niveles de expresión de esos genes fueron altos en los pacientes alérgicos no tratados con respecto a los sanos voluntarios y disminuyeron con la ITAE aunque no llegaron a los niveles de los individuos sanos. Esa disminución fue detectada también en las proteínas de los genes de IL17 y sus genes asociados (IL6 e IL23) en un inmunoensayo enzimático en plasma. También se observó una correlación positiva entre los niveles de ARN mensajero y las proteínas del gen de IL17 
con el puntaje de síntomas alérgicos ${ }^{11}{ }^{12}$. Las frecuencias de células $T$ auxiliares de tipo 17 disminuyeron y de las células T auxiliares secretoras de la citoquina IL-10 aumentaron después de la ITAE con respecto antes de recibir tratamiento. Por todo lo anterior, se concluyó que la ITAE inhibe la inflamación mediada por las células T auxiliares tipo 17 en la rinitis alérgica a ácaros de polvo doméstico y que la determinación de la expresión génica de la IL17 es un diagnosticador posible de la severidad de la enfermedad y del efecto de la ITAE a los dos años de tratamiento.

\section{Selección de pacientes posibles respondedores}

Los diagnosticadores predictivos son aquellos que permiten incluir aquellos pacientes que responderán al tratamiento o excluir aquellos que no se beneficiarán de la ITAE. Se ha empleado en las enfermedades alérgicas alimentarias de aquellos individuos que comparten los antígenos leucocitarios de histocompatibilidad tipo II (HLA, de sus siglas en inglés): HLA DR4+ y HLA DR15+ ${ }^{13}$. Ese diagnóstico también se ha aplicado en las enfermedades celíacas y en la esclerosis múltiple. Estas dos enfermedades autoinmunes tienen una causa poligénica multifactorial con un riesgo genético altamente relacionado con los genes de HLA tipo II. Los individuos celíacos del ensayo con el candidato inmunoterapéutico Nervax 2 (Immusan T, Massachusetts, Estados Unidos de América) fueron incluidos en una de las tres cohortes de acuerdo si son homocigotos o no para los genes codificantes DQA1*05 y DQB1 ${ }^{*} 2^{14}$. Los alelos DQA1 y DQB1 codifican la proteína heterodimérica alfa beta que reside en las células presentadoras de antígeno y facilita la interacción con el receptor de las células T CD4+ y el péptido de gluten. Estos genes representan entre el 80 y $90 \%$ de los pacientes celíacos en la población de Australia, Nueva Zelandia y Estados Unidos y también de Cuba ${ }^{15}$. Ese genotipaje es realizado en la RCP mediante el empleo de cebadores específicos de cada uno de las secuencias de esos alelos. Además de ese genotipaje se realizó la determinación in vitro de la actividad de células T específicas de los pacientes mediante un inmunoensayo enzimático de interferón gamma en sangre después de un desafío con los péptidos constituyentes de la vacuna ${ }^{16}$.

Los enfermos de esclerosis múltiple secundaria progresiva seleccionados en un ensayo con ITAE intradérmica de una mezcla de 4 péptidos de la proteína básica de mielina ATX-MS-1467 (Bubendorf, Suiza) tienen los alelos DRB1 ${ }^{\star} 01,04,07,11,13,14$, y $15^{17}$. Esos alelos constituyen un $77 \%$ de frecuencia del haplotipo caucasiano y tienen una asociación de susceptibilidad con esta enfermedad. Los alelos de HLA-DRB1 fueron diagnosticados por el genotipaje de baja resolución mediante la RCP de polimorfismo de conformación de cadena simple estándar en ADN extraído de leucocitos sanguíneos periféricos. En el caso de Cuba, se ha logrado identificar una susceptibilidad a esta enfermedad en los alelos DRB1*15 y 14 y DQA1*01 y DQB1*06 y una asociación de protección en el alelo $\mathrm{DRB} 1^{\star} 11$ con la esclerosis múltiple ${ }^{18}$. Se concluyó que esos dos candidatos a vacunas son seguros y que el primero fue efectivo en reprogramar las células T CD4+ al evitar la inflamación de las células intestinales después de varios desafíos de los pacientes al gluten.

\section{Favorecer el estudio de la combinación de medicamentos}

Se evaluó el efecto de las células B sobre las células dendríticas a través de la expresión del gen tromboespondina-1 (TSP1) en producir tolerancia en un modelo animal de alergia alimentaria a ovoalbúmina y como la ITAE se puede combinar con un tratamiento antilL-13 para mejorar ese proceso ${ }^{19}$ El ARN total fue aislado de las células del intestino, bazo y nódulos mesentéricos de los ratones sometidos al tratamiento por vía oral y a la inyección 48 horas después del inicio del ITAE con un antagonistas antilL-13. Se obtuvo ADN complementario donde se analizó la expresión de TSP1 en la RCPC. También, se realizó Western Blot y la RCP específica de metilación de ese gen. La exposición a la citoquina IL-13 inhibió la expresión de TSP1 en células $B$, y mejoró la metilación de ADN del gen TSP1. El tratamiento de los ratones con alergia alimentaria con la combinación de ITAE y antagonistas antilL-13 restauró la generación de células dendríticas tolerogénicas y mejoró el efecto terapéutico de la inmunoterapia. Las células B fueron requeridas en la generación de células dendríticas productoras del factor de crecimiento transformante beta o TGF beta. La TSP1 derivada de células B convirtió el TGF beta latente en activo en las células dendríticas por una reacción proteolítica.

\section{Estudio de las dosis óptimas de la inmunoterapia de antígeno específico.}

A los niños con rinitis alérgica de un ensayo clínico se dividieron en tres grupos de dosis acumulativa semanal: 200 000 SQ-U, 24000 SQ-U y 0 SQ-U (placebo) de una mezcla glicerinada de polen de abedul, avellana y aliso (ALK-Abello, Hørsholm, Dinamarca) por vía sublingual ${ }^{12}$. De su sangre periférica se le extrajo las células mononucleares antes, al año y a los 2 años de tratamiento que fueron estimuladas in vitro con derivados de las proteínas purificadas del Mycobacterium tuberculosis, con el alérgeno y otro grupo no fue estimulada. De esas células se extrajo el ARN mensajero en lo que se estudiaron los genes siguientes en la RCPC: IL17, IL23, IL27, FOXP3 (factor de transcripción regulador de desarrollo de las células T regulatoria), IL10 y TGFB1 (gen del factor de crecimiento transformante beta). La expresión del gen de IL17 inducida por el alérgeno fue significativamente aumentada en los pacientes con una alta puntuación combinada de síntomas y medicamentos (parámetro que se incrementa por cada síntoma y su intensidad y tipos de medicamentos administrados) de dos años. También, existió correlación positiva entre los niveles de expresión del gen de IL17 y esa puntuación en el grupo total de estudio y fundamentalmente con el grupo tratado con mayor dosis al cabo de 2 años ( $r=0,74 ; p=0,027)$. La expresión del gen FOXP3 inducida por el alérgeno fue significativamente aumentada en el grupo tratado con la máxima dosis acumulativa semanal después de 2 años de estudios cuando se compara con antes de recibir tratamiento $(p=0,016)$ y con el grupo placebo $(p=0,028)$. Se encontró una correlación en la expresión de los genes IL10 y TGFB1 con el gen FOXP3 en el estudio total. Este último gen está relacionado con las células T regulatorias específicas de alérgeno que también aumentaron durante el tratamiento.

En un estudio preclínico en ratones transgénicos con encefalitis autoinmune experimental que constituye un modelo de estudio de la esclerosis múltiple se evalúo como el escalado de las dosis de la ITAE subcutánea $(0,08 ; 0,8 ; 8 ; 80$ y $800 \mu \mathrm{g}$ de proteína básica de mielina) influye en los perfiles transcripcionales e inmunológicos de las células $T$ auxiliares ${ }^{20}$. Se realizó microarreglos de ADN a las células T auxiliares aisladas y luego, se confirmaron sus hallazgos con la RCPc. También se realizó análisis de citometría de flujo y de proliferación celular. A partir de $8 \mu \mathrm{g}$ de antígeno se produce anergia proliferativa y disminuyen las citoquinas asociadas con las células $T$ auxiliadoras de tipo 2 (IL-2 e interferón gamma). Mediante un análisis multivariado de datos para agrupamientos de genes, visualización y análisis de componentes principales se reveló una progresiva supresión de transcriptos que regulan positivamente 
las funciones efectoras inflamatorias y reprimen las vías del ciclo celular. Los genes de los factores de transcripción: CMIP (gen de la proteína inductora de c-maf) y NFIL3 (gen del factor nuclear regulado de la proteína IL-3) aumentaron su expresión al igual que los genes de las moléculas coestimulatorias negativas: LAG3 (gen 3 de activación de linfocitos), TIGIT (gen del inmunoreceptor de células T con dominio de lg y motivo inhibitorio basado en tirosina), y HAVCR2 (gen del receptor celular 2 del virus de hepatitis A) a nivel de ARN mensajero y proteína. Esas moléculas caracterizan a las células T auxiliares regulatorias y su expresión correlaciona con la citoquina inmunoregulatoria IL-10. Estos patrones de expresión de transcriptos coordinados y específicos de estadios evolutivos suministran una racionalidad en el escalado de dosis del ITAE que permita minimizar los riesgos asociados con la administración tanto profiláctica como terapéutica de esa vacuna y lograr una modulación sostenida de esas células T auxiliares específicas de antígeno.

\section{Descubrir el mecanismo de acción de la inmunoterapia de antígeno específico}

El mecanismo clave de esta inmunoterapia es lograr la tolerancia periférica sostenida mediante la presentación antigénica en un contexto no inflamatorio. Las células T CD4+ requiere de tres señales cuando interactúa con las células presentadoras de antígenos: 1) una señal de especificidad para la unión del receptor de célula T CD4+con un péptido antigénico corto presentado por el complejo mayor de histocompatibilidad tipo 2 (MHCII), 2) una señal de coestimulación negativa suministrada por un número diferente de pares de ligando-receptor sobreexpresado en un ambiente no inflamatorio y 3) una señal de regulación mediante citoquinas inhibitorias ${ }^{21}$.Esas tres señales genera células T anérgicas, apoptosis de células T CD4+ efectoras o la generación de células T regulatorias. Si la ITAE actúa a nivel de las células T virgen de contacto con el antígeno se favorece la apoptosis de aquellas que son específicas para los péptidos de la vacuna o induce la diferenciación de las células T regulatorias. Esas células T regulatorias inhiben las células $T$ memorias efectoras patogénicas y además, suprimen la diferenciación de otras células T virgen que reconocen otros antígenos propios liberados como resultados de un daño tisular y evitan así, la expansión epitópica. Si la vacuna influye directamente a nivel de las células $T$ de memoria promueve la apoptosis y su anergia ${ }^{22}$. También, es importante la dosis de antígeno para inducir tolerancia. A bajas dosis se favorece la anergia mientras la exposición crónica y repetida a altas dosis de ese antígeno se favorece la conversión de células T efectoras altamente diferenciadas en células $T$ regulatorias secretoras de la citoquina IL-10 de cada fenotipo (T auxiliadoras de tipo 1, 2 y 17). Por eso se recomienda realizar esquema de incremento gradual de dosis. Primero, se comienza con bajas dosis de antígeno y se incrementa hasta llegar a una alta dosis de mantenimiento donde se logra la inmunosupresión sin la posibilidad de efectos colaterales peligrosos. Con ese estímulo inicial de alta dosis antigénica pudiera ocurrir la activación y proliferación de células T CD4+ y la concomitante liberación excesiva de citoquinas.

El fenómeno de tolerancia periférica es un proceso multipaso donde participan órganos linfoides y tejidos periféricos ${ }^{23}$. Primero, ocurre la migración de las células dendríticas cargadas de antígenos de la lámina propia hacia los nódulos linfáticos locales. En estos nódulos las células estromales y las células dendríticas inducen la expresión de los receptores de localización en las células T específicas a antígenos y, además, favorecen su diferenciación en células T regulatorias FOXP3+ inducida y dependiente TGF beta. Estas células regulatorias inducidas regresan a la lámina propia periférica donde se expanden bajo la influencia de los macrófagos secretores de la citoquina IL-10. Algunas de esas células T regulatorias pasan de ese tejido periférico por vía linfática o sanguínea a diseminarse a través del sistema inmune y promueven la tolerancia local a nivel sistémico.

Todos los genes mencionados en esta revisión fueron confirmados por otra técnica independiente a la que se obtuvo su descubrimiento y pueden ser recogidos en cinco mecanismos por el orden de aparición una vez comenzada la administración de este tratamiento: a) la existencia de un ambiente protolerogénico y adyuvante en el sitio de administración de la ITAE, b) los efectos de desensibilización muy temprano (de horas a días) relacionados con células efectoras: los basófilos y las células B, c) los efectos de desensibilización temprano (a los pocos meses) relacionados con las células presentadoras de antígeno, d) los efectos intermedios de inducción de tolerancia (de meses a 2 años) en las células T periféricas, e) los efectos tardíos de inducción de tolerancia ( de 2 a 4 años) en la generación de células $B$ regulatorias (tabla 1 y figura 1 ). De esos procesos principales en el mecanismo de la ITAE se explicarán a continuación la existencia de un ambiente tolerogénico en la vía de administración y la desensibilización mediada por los basófilos, las células T y las células B.

Con el objetivo de estudiar el microambiente de citoquinas y la expresión de estructuras dianas para adyuvantes en la región sublingual, tejido gingival y bucovestibular de la mucosa oral con respecto a la piel se recogió muestras de biopsias y raspado oral de 20 individuos antes de las 24 horas después de muerto ${ }^{24}$. Se evaluó laexpresión de genes en la RCPc de las células T auxiliadoras tipo 1 (TBX21 o gen del factor de transcripción de diferenciación de este tipo de células T e IFNG o gen del interferón gamma); tipo 2 (GATA3 e IL4); tipo 17 (IL17A, IL17F, IL22, IL6, IL16, CCL20 o gen del ligando 20 de quemoquina tipo CC y RORC) y tipo regulatoria (FOXP3, IL10 y TGFB1) y las células dendríticas (TLR2 y TLR4,o genes de los receptores 2 y 4 parecidos a Toll). También se analizó las proteínas expresadas de esos genes en citometría de flujo e inmunohistoquímica. Descubrieron que la región vestibular y sublingual de la mucosa oral tienen propiedades protolerogénicas. Ambas regiones forman un microambiente de células T auxiliadoras tipo 1 predominante con respecto a la presencia de células T auxiliadoras tipo 2 que no fue detectada en ninguno de los sitios estudiados. También existe un microambiente de células T auxiliadoras tipo 17 de protección contra la actividad microbiana. Existe gran número de células dendríticas en la mucosa oral donde se detecta una gran expresión de receptores de esas células (TLR2 y TLR4), más en la región vestibular que en la región sublingual; que pueden emplearse como estructuras dianas de adyuvantes. Por tanto, la región vestibular puede ser un sitio de administración alternativo y atractivo de vacunas que usen la mucosa oral.

En dos estudios se mejora la comprensión de los basófilos sanguíneos en el mecanismo temprano de desensibilización alérgica de la ITAE subcutánea. De los pacientes con rinitis alérgica tratados con la ITAE de extracto alergoide Der pl Depigoid (Leti, Madrid, España) y los controles enlazados por edad y sexo se recogió muestra de sangre periférica antes del tratamiento y 4 horas después ${ }^{25}$. Se realizó la RCPc de los genes de la histamina $\mathrm{N}$-metiltranferasa (HNMT) y la triptasa alfa/beta 1 (TSPAB1) que están relacionados con mediadores alérgicos. Los basófilos sanguíneos de los pacientes bajo tratamiento tienen un aumento de la expresión de lgE unida a receptor, el cual está correlacionado con la lgE total sérica y una disminución en la expresión génica 
de HNMT y la TSPAB1 cuando se compara con los alérgicos sin esta inmunoterapia. Existe una correlación negativa significativa entre la expresión del gen HNMT y el tiempo bajo tratamiento. También, en otro estudio de los basófilos purificados de sangre periféricas de pacientes tratados con ITAE de veneno de avispa y sujetos controles, se investigó la influencia de la expresión de los genes de los receptores de histamina 1, 2 y 4 (H1R, H2R y H4R) sobre el receptor de alta afinidad de lgE y la liberación de histamina y de leucotrieno mediante la RCPc, la citometría de flujo y el inmunoensayo enzimático ${ }^{26}$. Se determinó una rápida regulación positiva del gen $\mathrm{H} 2 \mathrm{R}$ dentro de las primeras 6 horas en la fase de inducción de la ITAE. Ese gen suprimió selectivamente la activación inducida del receptor de alta afinidad de lgE y la liberación de los mediadores químicos y también la producción de citoquina in vitro.

En varios estudios con respecto al efecto de desensibilización de las células T por la ITAE se sugiere que la respuesta inmune de células $T$ auxiliadoras tipo 2 es poco modificada o es inhibida transcripcionalmente por una respuesta aumentada de células T auxiliadoras tipo 1 y la existencia de un efecto regulatorio mutuo con un equilibrio dinámico entre células T regulatorias y las células T gamma delta con la cadena variable gamma III en la rinitis alérgica antes y después de una inmunoterapia efectiva de 1 año. También se analizó el efecto de esa inmunoterapia sobre la vía de señalización de la citoquina IL-4, sobre las vías de apoptosis de esas células y la población de células T de memoria anérgicas y tolerogénicas. En el primer estudio se estudió el efecto de las dosis sobre la expresión de los genes IL18, SLAMF1 (gen de la molécula de activación linfocítica de señalización) y GATA3 ${ }^{27}$. La expresión de ARN mensajero de IL18 fue aumentada en el grupo de alta dosis en comparación al placebo después de 1 año de terapia ( $p=0.028$ ) y tuvo una correlación inversa con la reacción cutánea de fase tardía en el segundo año $(r=-0,41$; $p=0,04)$. La expresión del gen de SLAMF1 aumentó en el grupo de dosis alta desde la línea base a 1 año $(p=0,028)$ y correlacionó con los ARN mensajeros de IL10 ( $r=0,096, p<0,0001)$ y de TGFB1 $(r=0,8 ; p=0,0037)$. No hubo cambios significativos en el ARN mensajero de GATA3. En otro ensayo clínico se estudia la expresión del gen FOXP3 y de la subfamilia de genes de la región variable del receptor de células Tgamma-delta (TRVG1, TRVG2 y TRVG3) a partir de la RCPc de ARN total purificado de las células T de sangre periférica ${ }^{28}$. Los niveles de expresión del gen FOXP3 y de los genes de la subfamilia de la cadena variable gamma de los receptores de células $T$ en los pacientes con rinitis alérgica fueron significativamente menores que en los sujetos saludables. La expresión de los genes TRVG1 y TRVG2 fue similar antes y después de la ITAE. Sin embargo, los genes FOXP3 y TRVG3 fueron significativamente mayores después de la ITAE que antes de ese tratamiento. Esos dos genes correlacionaron negativamente con la puntuación análoga visual de síntomas alérgicos (escala de 0 a 10: de mínimo a máximo malestar). Los niveles de expresión de los genes TRVG1 y TRVG2 correlacionaron positivamente con los niveles de expresión de FOXP3 antes de la ITAE. Sin embargo, los niveles de expresión de TRVG3 correlacionaron significativamente con FOXP3 antes y después de la ITAE.

Se analizó el efecto sobre los niveles de expresión de los genes del receptor soluble (sIL4R) y del receptor unido a membrana de IL4 (IL4R) en pacientes tratados con ITAE mediante la RCPc a partir de células mononucleares de sangre periférica in vivo y ex vivo ${ }^{29}$. Además, se revisaron los datos almacenados digitalmente de un microarreglo de los diferentes tipos de células T auxiliadoras 1, 2, 17 y regulatoria para evaluar la expresión de ese receptor. EL ITAE produce una disminución del gen IL 4 R y de la citoquina IL-
4. Este receptor se encuentra representado en todas las células T auxiliadoras, pero es más abundante en las células $T$ auxiliadoras tipo 2. Es decir, que su disminución en la expresión por el tratamiento no sólo representa una disminución a nivel molecular sino también a nivel celular. El gen slL4R aumenta su expresión por el ITAE. Estos cambios de los genes de sIL4R e IL4R concuerdan con los obtenidos a nivel de sus respectivas proteínas en el suero de los pacientes en un inmunoensayo. El efecto inhibitorio del receptor soluble y el efecto potenciador del receptor unido a membrana en la señalización de la citoquina IL-4 es una explicación inmunológica a nivel básico y clínico novedosa del mecanismo de la ITAE en los pacientes tratados.

Se tomó células mononucleares de sangre periférica en descanso de niños con alergia alimentaria al maní tratados con ITAE oral y se aislaron las células T con moléculas de superficie CD3+. Se realizó microarreglo de ADN de esas células T y se detectó una expresión disminuida de los genes de apoptosis a los 6 meses con respecto antes de tratamiento ${ }^{30}$. Esos genes fueron: BCL2L11, GADD45A, TNFSF8 y RELA. El primero corresponde a la regulación de apoptosis mediante proteínas mitocondriales; el segundo, a la apoptosis dependiente de p53 y el tercero y el cuarto, a la vía antiapoptótica TNFs/NF-kappaB/IAP. Este resultado refleja lo que sucede para la población general de células T, pero no es lo esperado para la células T auxiliadoras tipo 2 efectoras específicas del antígeno en donde debe estar aumentada su apoptosis. Los autores sugieren que primero se realice una separación de esas células mediante complejos de tetrámeros de MHCll con los péptidos de ese alérgeno en citometría de flujo y luego, la determinación de expresión de genes.

Se realizó un perfil transcripcional con alrededor de 22 genes en RCPc de alto flujo basada en la tecnología de microfluido Fluidigm Biomark System ${ }^{\circledR}$ (Fluidigm Corporation, California, Estados Unidos de América) a nivel de una simple célula separadas de monocitos de sangre periféricas de individuos alérgicos al maní por reactivos de dextrámeros de moléculas del MHCII con los péptidos del alérgeno Ara $h 2$ en citometría de flujo activada por fluorescencia ${ }^{13}$.Mediante un análisis multivariado de los datos de los genes se descubrió que las células T auxiliadoras de los clones de receptores de células $T$ diverso se expandieron en frecuencia y cambiaron de un fenotipo alérgico (IL4+/IL13+) y regulatorio (FOXP3+/CD25+/IL10+) a un fenotipo anérgico (CD28-/ CD38-/IFNG-/IL3-/IL4-/IL10-) y no alérgico (IFNG+). Estos cambios fueron asociados con una disminución de los síntomas alérgicos y al desarrollo de una tolerancia inmune operacional. La administración de antígeno de manera repetida fue crítico en lograr que ese fenotipo anérgico de memoria de larga vida (CD28-/ MKI67-/CD69- o con baja expresión/CD45RA con baja expresión) aumentara gradualmente sobre los demás subtipos de células T auxiliadoras y se favorezca una memoria anérgica y un ambiente tolerogénico.

La generación de células B regulatorias se producen en pacientes alérgicos tratados con la ITAE de fosfolipasa A2 (alérgeno principal de veneno de abeja) y tiene una potente supresión de la proliferación de células T CD4+ de antígeno específico y un aumento de la expresión de la lgG431. En un ensayo preclínico de un modelo de ratón de alergia alimentaria con ovoalbúmina ${ }^{32}$.Se estudió que efecto provocaba la ITAE con ese antígeno y con el agente probiótico Clostridium butyricum sobre la inflamación intestinal del ratón. Se aplicó la RCPc para determinar la expresión de los genes de IL10, BCL6 (gen de la proteína 6 del linfoma de células B) y IGHE (gen de la lgE) y también se realizó Western Blot y citometría de flujo. Se comprobó in vitro que la células B antígeno específica del bazo del ratón tratada con la combinación 


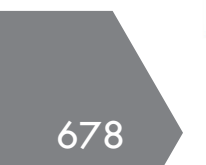

\begin{tabular}{|c|c|c|}
\hline $\begin{array}{l}\text { Mecanismo de } \\
\text { acción }\end{array}$ & Células & Expresión de genes (nombre de gen*) \\
\hline $\begin{array}{l}\text { Existencia de un } \\
\text { ambiente } \\
\text { adyuvante y } \\
\text { protolerogénico } \\
\text { en el sitio de } \\
\text { administración. }\end{array}$ & $\begin{array}{l}\text { Células T y } \\
\text { dendríticas de la } \\
\text { región } \\
\text { sublingual, } \\
\text { gingival y } \\
\text { vestibular de la } \\
\text { mucosa oral y } \\
\text { piel }\end{array}$ & $\begin{array}{l}\text { Aumento de los siguientes genes de citoquinas y factores de } \\
\text { transcripción de la mucosa oral con respecto a la piel: a) gen } \\
\text { de la Interleucina } 10 \text { o IL-10 (IL10), gen del factor de } \\
\text { crecimiento transformante beta (TGFB1) y gen del factor de } \\
\text { transcripción regulador del desarrollo y función de las células } \\
\text { T regulatorias (FOXP3); b) gen de interferón gamma (IFNG) } \\
\text { y gen de la proteína } 21 \text { de la caja T (TBX21); c) genes de los } \\
\text { receptores } 2 \text { y } 4 \text { parecido a Toll (TLR2 y TLR4); d) gen de } \\
\text { IL-17 (IL17) y gen del receptor C huérfano del receptor de } \\
\text { ácido retinoico (RORC). } \\
\text { No se detectaron los genes de } \mathbb{L}-4 \text { (IL4) ni de la proteína } 3 \\
\text { de unión GATA (GATA3). }\end{array}$ \\
\hline \multirow[t]{2}{*}{$\begin{array}{l}\text { Disminución de la } \\
\text { cantidad y función } \\
\text { de células } \\
\text { inflamatorias. }\end{array}$} & $\begin{array}{l}\text { Basófilos. } \\
\text { Estudio in vitro. }\end{array}$ & $\begin{array}{l}\text { Disminución del gen de la histamina N-metil transferasa, } \\
\text { (HNMT) y del gen de la Triptasa AB1 (TSPAB1), } \\
\text { Aumento del gen receptor de histamina } 2 \text { (H2R) }\end{array}$ \\
\hline & $\begin{array}{l}\text { Células B } \\
\text { intestinales, } \\
\text { bazo y nódulos } \\
\text { mesentéricos. } \\
\text { Estudio in vitro. }\end{array}$ & Aumento del gen de la tromboespondina 1 (TSP1 ० THBS1). \\
\hline $\begin{array}{l}\text { Generación de } \\
\text { células dendríticas } \\
\text { tolerogénicas. }\end{array}$ & $\begin{array}{l}\text { Células } \\
\text { dendríticas } \\
\text { Regulatorias. } \\
\text { Estudio in vivo. }\end{array}$ & $\begin{array}{l}\text { Aumento de los genes del componente } 1 \text { del complemento } \\
\text { (CQ1), del gen del receptor de lipoproteína de baja densidad } \\
\text { acetilada (STAB1) y del receptor IIIA para la IgG } \\
\text { (FCGR3A). }\end{array}$ \\
\hline \multirow[t]{3}{*}{$\begin{array}{l}\text { Presencia o } \\
\text { generación de } \\
\text { células T } \\
\text { tolerogénicas o } \\
\text { anérgicas o } \\
\text { regulatorias. }\end{array}$} & $\begin{array}{l}\text { Células } \\
\text { mononucleares } \\
\text { periféricas. } \\
\text { Estudio ex vivo. }\end{array}$ & $\begin{array}{l}\text { Aumento de los genes } \mathbb{I} 10 \text {, TGFB1 y FOXP3. } \\
\text { Disminución del gen } \mathbb{L} 17\end{array}$ \\
\hline & $\begin{array}{l}\text { Células T } \\
\text { gamma delta. }\end{array}$ & $\begin{array}{l}\text { Aumento del gen de la región variable tipo III de la cadena } \\
\text { gamma del receptor de células T (TRVG3). }\end{array}$ \\
\hline & $\begin{array}{l}\text { Células T } \\
\text { anérgicas } \\
\text { específicas de } \\
\text { antígeno. } \\
\text { Estudio in vitro. }\end{array}$ & $\begin{array}{l}\text { Disminución del gen marcador de célula de memoria inactiva } \\
\text { de largo plazo CD4SRA (PTPRC, gen del receptor tipo C de } \\
\text { la proteína tirosin fosfatasa), del gen marcador de } \\
\text { proliferación Ki-67 (MKI67), del gen marcador de activación } \\
\text { linfocitaria temprana (CD69), del gen de la glicoproteína de } \\
\text { superficie CD28 específica de células T (CD28) y del gen de } \\
\text { la enzima bifuncional adenosin difosfato ribosa ciclasa y } \\
\text { adenosin difosfato ribosa cíclico hidrolasa } 1 \text { (CD38). }\end{array}$ \\
\hline \multirow{3}{*}{$\begin{array}{l}\text { Desviación de la } \\
\text { respuesta inmune } \\
\text { de un patrón de } \\
\text { células } T \\
\text { auxiliadoras tipo } 2 \\
\text { a células } T \\
\text { auxiliadoras tipo } \\
1 \text {. }\end{array}$} & $\begin{array}{l}\text { Macrófagos y } \\
\text { Células T }\end{array}$ & $\begin{array}{l}\text { Aumento del gen de IL18 y del gen de la molécula de } \\
\text { activación linfocítica de señalización (SLAMF1). }\end{array}$ \\
\hline & $\begin{array}{l}\text { Células T } \\
\text { periféricas. } \\
\text { Estudio ex vivo. }\end{array}$ & $\begin{array}{l}\text { Disminución del gen de la citoquina IIL-4 (IL4) y del gen } \\
\text { receptor de membrana de la II-4 (IL } 4 R \text { ) y aumento del gen } \\
\text { del receptor soluble de la IL-4 (sIL } 4 R \text { ). }\end{array}$ \\
\hline & $\begin{array}{l}\text { Células } \\
\text { dendríticas tipo } \\
2 \text { y células T. } \\
\text { Estudio in vivo }\end{array}$ & $\begin{array}{l}\text { Disminución del gen GATA3, del gen de la proteína quinasa } \\
\text { serina/treonina } 4 \text { con interacción al receptor (RIPK4) y del } \\
\text { gen de la trombomodulina o CD141 (THBD). }\end{array}$ \\
\hline $\begin{array}{l}\text { Influencia sobre la } \\
\text { apoptosis de } \\
\text { células } T\end{array}$ & $\begin{array}{l}\text { Células T } \\
\text { periféricas. } \\
\text { Estudio in vitro. }\end{array}$ & $\begin{array}{l}\text { Disminución del gen facilitador de la apoptosis } 11 \text { parecido a } \\
\text { BCL2 (BCL2L11), del gen alfa inducible de daño del ácido } \\
\text { desoxirribonucleico y parada del crecimiento (GADD } 45 A \text { ), } \\
\text { del gen miembro } 8 \text { de la superfamilia del factor de necrosis } \\
\text { tumoral (TNFSF8) y del proto-oncogen homólogo A de } \\
\text { reticuloendoteliosis viral (RELA). }\end{array}$ \\
\hline $\begin{array}{l}\text { Presencia de } \\
\text { células B } \\
\text { regulatorias }\end{array}$ & $\begin{array}{l}\text { Células B } \\
\text { específicas de } \\
\text { antigeno. } \\
\text { Células de la } \\
\text { lámina propia } \\
\text { intestinal y del } \\
\text { bazo. }\end{array}$ & $\begin{array}{l}\text { Aumento del gen II } 10 \text {, del gen de la proteína } 6 \text { de linfoma B } \\
\text { (BCL6) y del gen de la región constante de la cadena pesada } \\
\text { de la Ig gamma } 4 \text { (IGHG4). }\end{array}$ \\
\hline
\end{tabular}

\section{Función biológica**}

Los genes $\mathbb{L} 10$, TGFB1 y FOXP3 están asociados a una respuesta $T$ auxiliadora regulatoria Los genes IFNG y TBX21 están asociados a una respuesta $T$ auxiliadora tipo 1 . El genTBX21 codifica un factor de transcripción de diferenciación de células T auxiliadora tipo 1 .

Los genes $\Pi 17$ y RORC están asociados con una respuesta auxiliadora tipo 17 . El gen RORC codifica el factor de transcripción de diferenciación de células $T$ auxiliadora tipo 17.

Los genes $\amalg 4$ y GATA3 están asociados a una respuesta $T$ auxiliadora tipo 2. El gen GATA3 codifica un factor de transcripción de diferenciación de células $T$ auxiliadora tipo 2

El gen HNMT codifica para una enzima del catabolismo de la histamina. El gen TSPAB1 codifica para un mediador proteolítico de la alergia. El gen H2R codifica para un receptor con actividad inmunosupresora sobre el receptor de alta afinidad de inmunoglobulina $(\mathrm{Ig}) \mathrm{E}$.

El genTSP1 codifica para una glicoproteina que favorece la conversión del factor de crecimiento transformante beta de una proteina inactiva en activa por medio de la proteólisis.

El gen CQ1 participa en la inmunidad innata y favorece el desarrollo de células dendríticas tolerogénicas. El gen FCGR3A codifica para ese receptor de IgG que participa en la citotoxicidad dependiente de anticuerpo y en la fagocitosis.

La citoquina codificada por el gen $\mathbb{I} 10$ disminuye la expresión de las moléculas del complejo mayor de histocompatibilidad tipo 2 (MHCII) y las moléculas coestimulatorias e inhibe la capacidad presentadora de antígenos de los monocitos y de los macrófagos activados. La citoquina del gen TGFB1 induce la expresión de FOXP3 y la conversión de las células T en regulatorias y su proliferación, favorece el cambio de subclase de IgG4 en las células B y la remodelación del tejido residente, disminuye la expresión de IgE específica de antígeno e inhibe los mastocitos, los basófilos y los eosinófilos. La citoquina del gen $I L 17$ activa las células no inmunes como las células endoteliales para que secreten quemoquinas facilitadoras de la migración de los monocitos al sitio de infección.

El gen TRVG3 codifica un polipéptido que forma parte de la estructura del receptor de las células T gamma delta que une un péptido antigénico con la MHCII.

El gen CD 38 codifica una glicoproteina transmembrana que es receptor de células de sistema inmune y participa en la transducción de señal a través de calcio y en la adhesión celular. El gen CD69 codifica un receptor participante en la proliferación celular y transductor de la señal en linfocitos, células NK y plaquetas. La glicoproteína de membrana codificada por el gen CD28 participa en las señales de coestimulación de las células $\mathrm{T}$.

E1 gen IL8 codifica una citoquina que favorece la

diferenciación de células $\mathrm{T}$ auxiliadoras tipo 1 .

E1 gen SLAMF1 codifica un receptor que favorece la proliferación de células activadas independiente de $\mathrm{IL}-2$ durante la respues

Esos genes participan en la vía de señalización de la csos genes participan en la la de senázacion de la cílu $\mathrm{c}$. celliń B y estion e eosinófilos, basófilos y mastocitos. El factor de transcripción codificado por el gen GATA3

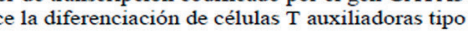
E1 gen THBD codifica para una proteína que favorec una respuesta de citoquina $T$ auxiliadora de tipo 2 . Ele detiva el factor de transcripción NF-kappa B.

Esos genes participan en las vías señalización de la apoptosis

E1 gen BCL6 codifica un factor de transcripción con actividad tolerogénica.

El gen IGHG4 codifica anticuerpos de la subclase $\mathrm{IgG} 4$ con actividad antiinflamatoria.

Nota: *Comité de nomenclatura de genes del proyecto de genoma humano (HUGO Gene Nomenclature Committee) tomado de https://www.genenames.org/cgi-bin/gene_symbol_report?hgne_id=HGNC:9955. ** Función enriquecida con la información del sitio: http://www.genecards.org/ que pertenece a la base de datos de Genes Humanos.

Tabla 1. Los genes de los diferentes mecanismos propuestos para la acción de la inmunoterapia de antígeno específico en las enfermedades alérgicas. 


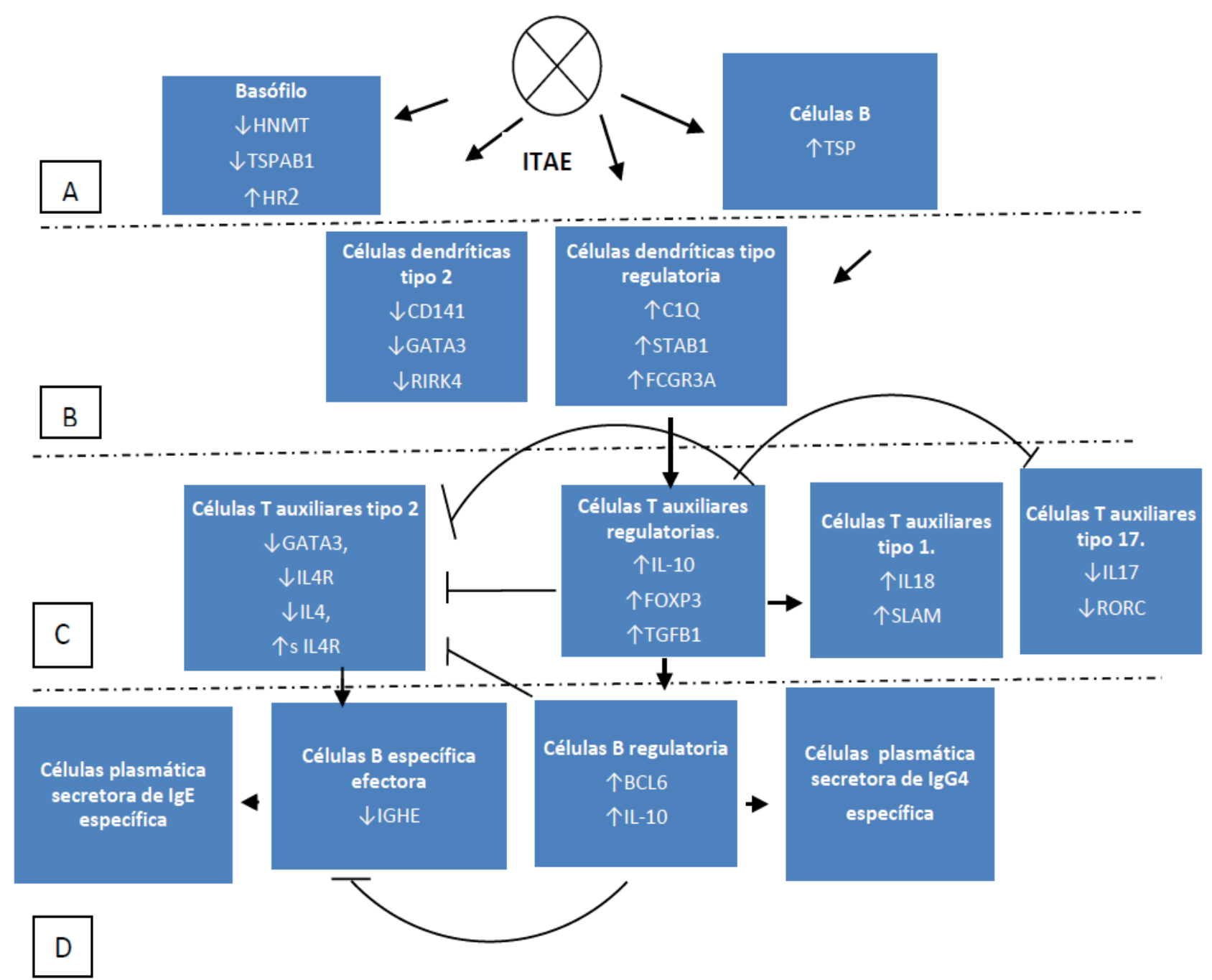

Figura 1. Diagrama de circuitos que muestra el efecto de la inmunoterapia de antígeno específico (ITAE) sobre la expresión de los genes en los diferentes compartimentos celulares (rectángulos) según el tiempo de aparición: A corresponde a los cambios muy rápidos; $\mathrm{B}$, a los cambios tempranos; $\mathrm{C}$, a los cambios intermedios y D, a los cambios tardíos. Se observa el eje central que forman las células dendríticas regulatorias, T regulatorias y B regulatorias y sus genes en inhibir la actividad de las células $T$ auxiliadores tipo 2 y tipo 17, las células B efectoras y las células plasmáticas generadoras de inmunoglobulina E específica y por otro lado, estimular las células T auxiliadoras tipo 1 y favorecer la diferenciación de células plasmáticas secretoras de lgG4 específica con actividad antiinflamatoria. Las flechas hacia arriba al lado de la nomenclatura de los genes significa aumento de la expresión; las flechas hacia abajo, disminución de la expresión de los genes. Las líneas con saetas son señales estimulatorias y las líneas sin saetas son señales inhibitorias.

ITAE y butirato de sodio se convierten en células $B$ regulatorias secretora de la citoquina IL-10 con aumento de la expresión de los genes BCL6 e IL10 y disminución de la expresión de IGHE. Mientras esas células fueron tratadas con el antígeno generaron células plasmáticas (CD138+) con disminución de BCL6 e IL10 y aumento de la expresión de IGHE. Esa acción del butirato de sodio fue dependiente de la vía de señalización del receptor de células B porque se pierde cuando se emplea un bloqueador de esa vía de señalización. La ITAE combinada con el agente probiótico disminuyó más la inflamación intestinal de los ratones que la ITAE sin ese agente.

Consideraciones sobre esos estudios de expresión de genes en la inmunoterapia de antígeno específico y su aplicación en las enfermedades autoinmune.

El desarrollo de la ITAE para enfermedades alérgicas y autoinmune requiere un enfoque multidisciplinario y es un camino largo de investigación donde se definan algunas partes claves como son: la configuración exacta de los epítopos o antígenos; los métodos de obtención y purificación de esos componentes; las dosis, las vías y frecuencia de su administración; el uso de adyuvantes adecuados; la identificación de parámetros inmunológicos efectivos para el monitoreo evolutivo de cada enfermedad y su posible correlación con la desensibilización o inducción de tolerancia; la combinación adecuada de esta inmunoterapia con otras como la antiinflamatoria no específica; un diagnóstico más temprano de la enfermedad para un inicio más precoz del tratamiento y una mayor efectividad; definir la población de pacientes respondedores y un diseño adecuado de los estudios preclínicos y clínicos que determinen su implementación final en el registro de salud pública. 33 En ese proceso de desarrollo de la ITAE para las enfermedades 
alérgicas se ha empleado la farmacogenómica en varias de sus partes importantes.

La selección de pacientes respondedores a la ITAE a través de la farmacogenómica no ha tenido un impacto en las alergias y sí parece tenerlo en las enfermedades autoinmunes. La utilización de las pruebas genéticas en la ITAE de estas enfermedades va a depender del grado de penetrancia de los genes en sus inmunopatogénesis, la frecuencia de estos genes predisponentes en la población afectada y por otro lado, en la no existencia de otras alternativas de tratamiento lo suficientemente eficaces. En el desarrollo de la ITAE de Nervax2 para la enfermedad celíaca no sólo se mide la presencia de los alelos HLA DQ2 sino también como los péptidos de la vacuna modifican la actividad de los linfocitos T de sangre periférica de estos pacientes. Estas pruebas garantizan con un alto valor predictivo el beneficio de esta inmunoterapia cuando el tratamiento de restricción dietética existente no es efectivo en todos los casos y es difícil lograr la adherencia de los pacientes a llevarlo a cabo. Algo parecido ocurre con las enfermedades alérgicas donde la ITAE subcutánea está indicada sólo en los pacientes con sintomatología de moderada a grave controlada y tienen altos títulos de lgE específica o una prueba reactiva cutánea específica al alérgeno. Se administra la ITAE para aumentar el beneficio sobre el riesgo que puede existir al someterlo a la exposición antigénica y la posibilidad de desencadenar una reacción de anafilaxia. Sin embargo, con la ITAE sublingual- donde no se ha reportado ningún evento adverso grave- algunos autores abogan para que sea utilizado como tratamiento de primera línea. Sobre todo, porque después de la primera consulta el paciente puede hacer el tratamiento en su casa.

En la búsqueda de diagnosticadores de eficacia clínica a la ITAE se empleó las ventajas de las técnicas farmacogenómicas conjuntamente con otras tecnologías como son: el Elispot, la citometría de flujo, el inmunoensayo enzimático y la proteómica. Con la farmacogenómica se reconoció una propiedad emergente como la existencia de un ambiente protolerogénico y inmunoadyuvante en la región vestibular mayor que en la sublingual de la mucosa oral y esta a su vez mayor que en la piel después del estudio de varios grupos de genes con diferencias funcionales y de localización celular. También, se descubrió nuevos genes expresados diferencialmente entre varias condiciones experimentales in vitro en células dendríticas derivadas de monocitos, y luego se realizó el análisis de muestras de sangre in vivo de esos genes mediante la RCPc. Donde se aprovechó su alta sensibilidad para consumir pequeños volúmenes de sangre, poca cantidad de células y sin realizar expansión celular in vitro ${ }^{34}$. De este modo, la RCPc estudia la respuesta inmune periférica con una disminución del consumo de tiempo al no aislarse las células mononucleares de la sangre y se evita activar las células inmunes o modular los niveles de ARN mensajero de citoquinas no relacionada con el objetivo de estudio (algo que sucede con las células purificadas).

Esos cambios en genes asociados con la DCreg y DC2 pueden ser usados para detectar temprano el inicio de la respuesta clínica por la ITAE y constituye un perfil temprano dentro del sistema inmune innato de la orientación ulterior de la respuesta inmune adaptativa como es la transición de una respuesta de células T auxiliadoras tipo 2 y tipo 17 a las células T auxiliadoras regulatorias y de tipo 1 . Esos posibles diagnosticadores deben ser confirmados en la práctica clínica mediante su validación en estudios prospectivos con una mayor cantidad de pacientes que reaccionan a diferentes alérgenos (polen de hierba y árboles, y ácaro del polvo doméstico) y su correlación con la respuesta terapéutica favorable. En el estudio de los ge- nes de las citoquinas y de las quemoquinas de los linfocitos $T$ a nivel sistémico con la RCPc se pudo observar asociación con la respuesta clínica al tratamiento, pero no se encontró asociación con el beneficio clínico como sí sucedió con los genes de las células dendríticas.

Esas alteraciones del perfil de expresión de genes de células T o B, basófilos y células dendríticas pueden ser diagnosticadores subrogados de la inmunoterapia y tienen la desventaja de su evaluación tras un procesamiento y ejecución compleja, lo cual puede hacer difícil su uso clínico rutinario. Sin embargo, pueden formar parte en las pruebas de concepto de vacunas para estas enfermedades a nivel de ensayos preclínicos y clínicos y participar en la decisión de que candidatos preventivos o terapéuticos de ITAE puedan pasar a la siguiente fase de desarrollo. También algunos investigadores han desarrollado protocolos de laboratorio que favorecen la utilización de estas tecnologías a partir de varias fuentes de sangre o tejido con estimulación antigénica (respuesta ex vivo) o sin ella en los estudios clínicos multicéntricos ${ }^{35,36,37}$.

Estas tecnologías farmacogenómicas se han empleado en la profundización de los mecanismos de la inmunoterapia para aumentar su eficacia y acortar el tiempo para lograr un beneficio precoz en la salud de los pacientes. La alta sensibilidad de estas tecnologías logra determinar las bajas concentraciones relativas de los genes de citoquinas y quemoquinas en los sitios locales de inflamación, lo cual puede ser más indicativo de los efectos inmunológicos de la ITAE que a nivel sistémi$\mathrm{Co}^{38}$. Cuando la frecuencia de las células inmune específicas sanguíneas es baja, la detección de las citoquinas y las quemoquinas de esas células es más difícil porque se diluyen en la mezcla de las moléculas secretadas por las células T o B con otras especificidades. El éxito de la ITAE depende de discriminar las células T reguladoras o efectoras autoantigénicas o alergénicas específicas periféricas o de memoria de las células T observadoras o expectantes. Por lo que, tener una información complementaria del balance fino del número de tipos y subtipos de células efectoras y regulatorias de la inmunidad innata y adquirida mediante citometría de flujo o Elispot es importante. También, se sugiere realizar una cinética en la determinación de las respuestas porque la supresión de algunos subtipos de células puede ser transitoria como ocurre con las células T auxiliadoras tipo 2 efectoras que se relocalizan en los órganos linfáticos centrales o porque ocurre infecciones virales en el paciente que pueden alterar el cuadro de la tolerancia inmune durante la ITAE ${ }^{39}$. Se debe identificar aquellos genes expresados que no sean correlacionados o corregulados entre sí (como la existente entre los genes LAG3, TIGIT y HAVCR2 con el gen IL10) para definir los factores genéticos esenciales y no redundantes que influyen en el éxito de la ITAE en modular mejor la respuesta inmune (figura 1 ).

Para estudiar la influencia de la ITAE sublingual de ácaro de polvo sobre el sistema neuroendocrino de los niños alérgicos se determinó las concentraciones de prolactina y la hormona adenocorticotropina o $\mathrm{ACTH}^{40}$. Las concentraciones de prolactina, de proteína catiónica de eosinófilos y de la citoquina IL-13 fueron disminuidas. Las concentraciones de ACTH no variaron. Se interpretó que la prolactina secretada por los linfocitos representa una disminución de la actividad de células T auxiliadoras tipo 2 y tiene poco efecto su función endocrina en la ITAE. El efecto de esa inmunoterapia sobre el sistema neuroendocrino se ha estudiado mediante la farmacogenómica cuando las hormonas y los neuropéptidos liberados por ese sistema modifican la expresión de los genes de sus receptores y sus factores de transcripción asociados en los linfocitos o como estos últimos modifican la expresión de los genes de 
esas moléculas al ponerse en contacto con los antígenos de la inmunoterapia y estimulan el sistema nervioso. En las enfermedades alérgicas existe un gran efecto placebo cuando los pacientes son tratados con algún medicamento, por los que la Organización Mundial de Alergia recomienda reportar la eficacia mínima relevante de la ITAE sublingual en el grupo tratado de un 20 - $30 \%$ mayor que el grupo no tratado ${ }^{41}$. En las enfermedades autoinmune se espera ese efecto, así como la influencia hormonal que puede existir por ser más frecuente en el sexo femenino y los cambios que ocurren en su evolución durante el embarazo y el climaterio.

Los mecanismos genéticos antes mencionados de la ITAE en las enfermedades alérgicas deben ser tenido también en cuenta en las enfermedades autoinmune porque en ambos casos se añaden al efecto patogénico inmunoregulatorio y ambiental. Los estudios farmacogenómicos aplicados a esta inmunoterapia en seres humanos con enfermedades alérgicas es mucho mayor que en las enfermedades autoinmune y han servido para ganar en la comprensión de los procesos de inducción de tolerancia de una manera mejorada y refinada, minimizar los riesgos asociados con el tratamiento y buscar estrategias de intervención inmune dirigida a moléculas dianas relacionadas con el mecanismo molecular de células T y B efectoras y regulatorias (figura 1). Estos mecanismos de desensibilización o inducción de tolerancia también pueden evitar o disminuir la respuesta inmune indeseada de agentes polipeptídicos en el tratamiento de otras enfermedades ${ }^{42}$.

\section{Conclusiones}

La farmacogenómica se ha empleado en el estudio de varias partes críticas del desarrollo de ITAE de autoantígenos y alérgenos. Se busca detectar lo más temprano posible con la farmacogenómica y otras tecnologías afines el aumento en el umbral de activación de las células efectoras y cambios en las células T y B que denoten disminución de sus poblaciones de memoria antígeno específico efectora y aumento de sus poblaciones antígeno específico regulatoria o anérgica de larga duración producto de la ITAE. Los cambios más temprano del efecto de las ITAE ocurre a nivel de las células inflamatorias efectoras y de las células dendríticas.

El estudio de los mecanismos de acción de la ITAE mediante la farmacogenómica facilita mejorar el proceso de inducción de tolerancia o desensibilización con esquemas más cortos y vías de administración más eficientes y segura en combinación o no con otros medicamentos, lo cual favorece la adherencia del paciente al tratamiento. Las enfermedades con una gran influencia del factor genético en la evolución y en el tratamiento favorece que las tecnologías farmacogenómicas sean empleadas para seleccionar a los pacientes que responderán a la ITAE.

La tendencia de las tecnologías farmacogenómicas en el desarrollo de la ITAE consiste en su utilización conjunta con otras pruebas para estudiar el sistema inmune, favorecer el desarrollo de diagnosticadores predictivos y subrogados y a los estudios de los mecanismo de acción de esta inmunoterapia, identificar nuevas dianas moleculares para desarrollar medicamentos y propiciar la generación de modelos animales con estas enfermedades lo más similar a las humanas que permitan un mejor examen de las células inmunotolerantes.

\section{Referencias bibliográficas}

1. Chae-Seo Rhee. Current Specific Immunotherapy for Allergic Rhinitis: Perspectives from Otorhinolaryngologists. Allergy Asthma Immunol Res. 2014 July; 6(4):273-275.

2. Venero-Fernandez SJ. Estadísticas de Asma. Cuba, 2016. Instituto Nacional de Higiene, Epidemiología y Microbiología. Disponible en http://files.sld.cu/alergia/files/2017/05/Estad\%C3\%ADsticas-de-Asma-2016.pdf [consultado 14 de marzo de 2018].

3. Cooper GS, Bynum MLK, Somersc EC. Recent Insights in the Epidemiology of Autoimmune Diseases: Improved Prevalence Estimates and Understanding of Clustering of Diseases.J Autoimmun. 2009; 33(3-4): 197-207.

4. Marth K, Focke-Tejkl M, Lupinek C, Valenta R, Niederberger V. Allergen Peptides, Recombinant Allergens and Hypoallergens for Allergen-Specific Immunotherapy.Current Treatment Options in Allergy 2014; 1:91-106. doi 10.1007/s40521-013-0006-5.Specific Immunotherap

5. Álvarez M, Castro RL, Gutiérrez DR, Labrada A, Enríquez I, Ronquillo $\mathrm{M}$ et al. Prescripción y vigilancia de la inmunoterapia sublingual con vacunas estandarizadas de ácaros domésticos en un servicio de alergología.VacciMonitor 2012; 21(3):13-18.

6. Cezmi A, Akdis CA, Akdis M. Mechanisms of allergen-specific immunotherapy and immune tolerance to allergens. World Allergy Organ J. 2015; 8(1): 1-12. doi: 10.1186/s40413-015-0063-2.

7. Goel G, King T, Daveson AJ, Andrews JM, Krishnarajah J, Krause $\mathrm{R}$, et al. Epitope-specific immunotherapy targeting CD4-positive $T$ cells in coeliac disease: two randomised, double-blind, placebo-controlled phase 1 studies. Lancet Gastroenterol Hepatol. 2017 Jul;2(7):479-93. doi: 10.1016/S2468-1253(17)30110-3.

8. Zimmer A, Bouley J, Le Mignon M, Pliquet E, Horiot S, Turfkruyer $M$ et al. A regulatory dendritic cell signature correlates with the clinical efficacy of allergen-specific sublingual immunotherapy. $J$ Allergy Clin Immunol 2012; 129 (4): 1020-30.

9. Gueguen C, Bouley J, Moussu H, Luce S, Duchateau M, Chamot-Rooke $\mathrm{J}$ et al. Changes in markers associated with dendritic cells driving the differentiation of either TH2 cells or regulatory $\mathrm{T}$ cells correlate with clinical benefit during allergen immunotherapy (abstract). J Allergy Clin Immunol. 2016 Feb;137(2):545-58. doi: 10.1016/j.jaci.2015.09.015.

10. Bonvalet M, Moussu H, Wambre E, Ricarte C, Horiot S, Rimaniol AC et al. Allergen-specific CD4+ T cell responses in peripheral blood do not predict the early onset of clinical efficacy during grass pollen sublingual immunotherapy. Clin Exp Allergy. 2012;42(12):1745-55. doi: 10.1111/cea.12015.

11. Li CW, Lu HG, Chen DH, Lin ZB, Wang DY, Li TY. In vivo and in vitro studies of Th17 response to specific immunotherapy in house dust mite-induced allergic rhinitis patients. PLoS One. 2014; 19;9(3):e91950. doi: 10.1371/journal.pone.0091950.

12. Nieminen K, Valovirta E, Savolainen J. Clinical outcome and IL-17, IL-23, IL-27 and FOXP3 expression in peripheral blood mononuclear cells of pollen-allergic children during sublingual immunotherapy (abstract). Pediatr Allergy Immunol. 2010; 21(1 Pt 2): e174-84. doi: 10.1111/j.1399-3038.2009.00920.x.

13. Ryan JF, Hovdea R, Glanvillea J, Lyua SCh, Jia X, Gupta S, et al. Successful immunotherapy induces previously unidentified allergen-specific CD4+ T-cell subsets. Proc Natl Acad Sci U S A. 2016;113(9):E1286-95. doi: 10.1073/pnas.1520180113.

14. ImmusanT, Inc. A Randomized, Double-Blind, Placebo-Controlled Study to Evaluate the Safety and Tolerability of Nexvax2 Preceded by a Dose Titration Period in Subjects With Celiac Disease Currently on a Gluten-Free Diet. https://clinicaltrials.gov/ct2/show/ NCT02528799 [consultado 20 abril 2017].

15. Cintado A, Sorell L, Galván JA, Martínez L, Castañeda C, Fragoso T et al. HLA DQA1*0501 and DQB1 ${ }^{*} 02$ in Cuban celiac patients. Hum Immunol. 2006;67(8):639-42. 
16. Ontiveros N, Tye-Din JA, Hardy MY, Anderson RP. Ex-vivo whole blood secretion of interferon (IFN)- $囚$ and IFN- $囚$-inducible protein-10 measured by enzyme-linked immunosorbent assay are as sensitive as IFN- $囚$ enzyme-linked immunospot for the detection of gluten-reactive $T$ cells in human leucocyte antigen (HLA)-DQ2,5(+) -associated coeliac disease. Clin Exp Immunol. 2014;175(2):30515. doi: 10.1111/cei.12232.

17. Streeter HB, Rigden R, Martin KF, Scolding NJ, Wraith DC. Preclinical development and first-in-human study of ATX-MS-1467 for immunotherapy of MS. Neurol Neuroimmunol Neuroinflamm. 2015;2(3):e93. doi: 10.1212/NXI.0000000000000093.

18. Fernández-de-Cossío ME, Cintado A, Nazabal M, Hanlet C, Díaz T, Villarreal A, et al. HLA-DRB1*1101 allele confer protection for Multiple Sclerosis disease in Cuban population. Bionatura. 2016; 1(4): 184-89. doi: 10.21931/RB/2016.01.04.5.

19. Yang G, Geng XR, Liu ZQ, Liu JQ, Liu XY, Xu LZ et al. TSP1-producing $\mathrm{B}$ cells restore $\mathrm{Ag}$ specific immune tolerance in an allergic environment. J Biol Chem. 2015; 290(20): 12858-67. doi: 10.1074/ jbc.M114.623421.

20. Burton BR, Britton GJ, Fang H, Verhagen J, Smithers B, Sabatos-Peyton CA et al. Sequential transcriptional changes dictate safe and effective antigen-specific immunotherapy. Nat Commun. 2014; 5:4741. doi: 10.1038/ncomms5741.

21. MacLeod MK, Anderton SM. Antigen-based immunotherapy (AIT) for autoimmune and allergic disease. Current Opinion in Pharmacology 2015, 23:11-16.

22. Anderson RP, Jabri B. Vaccine against autoimmune disease: antigen-specific immunotherapy. Curr Opin Immunol. 2013;25(3):410 7. doi: 10.1016/j.coi.2013.02.004.

23. Pabst $O$ and Mowat AM. Oral tolerance to food protein. Mucosa Immunology 2012; 5 (3): 232-39.

24. Allam J-P, Duan Y, Winter J, Stojanovski G, Fronhoffs F, Wenghoefer $M$, et al. Tolerogenic T cells, Th1/Th17 cytokines and TLR2/ TLR4 expressing dendritic cells predominate the microenvironment within distinct oral mucosal sites. Allergy 2011; 66: 532-39.

25. Lopes A, Azenha P, Teodósio C, Inácio M, Silva I, Loureiro G, et al. Impact of allergic rhinitis and specific subcutaneous immunotherapy on peripheral blood basophils of patients sensitized to Dermatophagoides pteronyssinus. Allergy Asthma Clin Immunol. 2013; 9(1): 40. doi: 10.1186/1710-1492-9-40

26. Novak N, Mete N, Bussmann C, Maintz L, Bieber T, Akdis M, et al. Early suppression of basophil activation during allergen-specific immunotherapy by histamine receptor J Allergy Clin Immunol. 2012;130(5):1153-58.e2. doi: 10.1016/j.jaci.2012.04.039.

27. Savolainen J, Nieminen K, Laaksonen K, Laiho T, Jacobsen L, Lahesmaa $R$, et al. Allergen-induced in vitro expression of IL-18, SLAM and GATA-3 mRNA in PBMC during sublingual immunotherapy. Allergy. 2007;62(8):949-53.

28. Zheng R, Wu X, Huang X, Chen Y, Yang Q, Li Y, et al. Gene expression pattern of Treg and TCR V凶 subfamily T cells before and after specific immunotherapy in allergic rhinitis. J Transl Med. 2014; 12: 24 doi: 10.1186/1479-5876-12-24

29. Nestor CE, Dadfar E, Ernerudh J, Gustafsson M, Björkander J , Benson $\mathrm{M}$ et al. Sublingual immunotherapy alters expression of IL-4 and its soluble and membrane-bound receptors. 2014; 69 (11):1564-66. doi: 10.1111/all.12505.

30. Jones SM, Pons L, Roberts JL, Scurlock AM, Perry TT, Kulis M, et al. Clinical efficacy and immune regulation with peanut oral immunotherapy. J Allergy Clin Immunol. 2009; 124(2): 292-300197. doi: 10.1016/j.jaci.2009.05.022

31. van de Veen W, Stanic B, Yaman G, Wawrzyniak M, Söllner S, Akdis DG et al. IgG4 production is confined to human IL-10-producing regulatory $B$ cells that suppress antigen-specific immune responses. J Allergy Clin Immunol. 2013;131(4): 1204-12. doi: 10.1016/j. jaci.2013.01.014.
32. Shi Y, Xu LZ, Peng K, Wu W, Wu R, Liu ZQ et al.Specific immunotherapy in combination with Clostridium butyricum inhibits allergic inflammation in the mouse intestine. Sci Rep. 2015 ;5:17651. doi: 10.1038/srep17651.

33. Maria F, Winner HL. Oral tolerance: Therapeutic implications for autoimmune diseases. Clin Dev Immunol 2006; 13(2-4): 143-157.

34. Stordeur P. Monitoring the immune response using real-time PCR. Methods Mol Biol. 2009:496: 323-38. doi: 10.1007/978-1-59745553-4_22.

35. Chakera A, Bennett SC, Cornall RJ. A whole blood monokine-based reporter assay provides a sensitive and robust measurement 0 the antigen-specific T cell response. J Transl Med 2011, 9:143. doi:10.1186/1479-5876-9-143.

36. Schultz-Thater E, Frey DM, Margelli D, Raafat N, Feder-Mengus C, Spagnoli GC et al. Whole blood assessment of antigen specific cellular immune response by real time quantitative PCR: a versatile monitoring and discovery tool. J Transl Med 2008, 6:58 doi:10.1186/1479-5876-6-58.

37. Lowe KB, Taylor JL, Storkus WJ. Monitoring Antigen-Specific T Cell Responses Using Real-Time PCR. Methods Mol Biol. 2014; 1186: 65-74. doi:10.1007/978-1-4939-1158-5_5.

38. Shamji MH, Kappen JH, Akdis M, Jensen-Jarolim E, Knol EF, Kleine-Tebbe $J$ et al. Biomarkers for monitoring clinical efficacy of allergen immunotherapy for allergic rhinoconjunctivitis and allergic asthma: an EAACI Position Paper. Allergy. 2017;72(8): 1156-73. doi: $0.1111 /$ all.13138.

39. Kücüksezer UC, Palomares O, Rückert B, Jartti T, Puhakka T, Nandy A et al. Triggering of specific Toll-like receptors and proinflammatory cytokines breaks allergen-specific T-cell tolerance in human tonsils and peripheral blood. J Allergy Clin Immunol. 2013;131(3):875-85. doi: 10.1016/j.jaci.2012.10.051.

40. Ippoliti F, De Santis W, Volterrani A, Lenti L, Canitano N, Lucarelli S et al. Immunomodulation during sublingual therapy in allergic children. Pediatr Allergy Immunol 2003:14:216-221.

41. Canonica GW, Cox L, Pawankar R, Baena-Cagnani CE, Blaiss M, Bonini S, et al. Sublingual immunotherapy: World Allergy Organization position paper 2013 update. World Allergy Organ J. 2014; 7(1): 6. doi: 10.1186/1939-4551-7-6.

42. van Brummelen EMJ, Willeke R, Wolbink G, Beijnen JH, Schellens JHM. Antidrug Antibody Formation in Oncology: Clinical Relevance and Challenges. Oncologist. 2016; 21(10): 1260-1268. doi: 10.1634/ theoncologist.2016-0061.

Recibido: 6 junio2018

Aprobado: 4 agosto 2018 